\title{
Perceptual Recovery Effects of Thyme Drops after Vocal Loading for Professional Voice Users: A Randomized Placebo- controlled Single-blind Trial
}

\author{
Ben Barsties v Latoszek ${ }^{1}$, Ewa v Latoszek ${ }^{2}$
}

\begin{abstract}
Objective: The present study aimed to evaluate perceived recovery effects of drops after vocal loading. Particularly, thyme was evaluated, which has promising effects on the mucosa, throat, and airway system.

Materials and methods: In total, 48 of 56 vocally healthy professional voice users were included because they presented with vocal fatigue after vocal loading. The subjects were randomized into two groups who received a thyme drop (TD), or a placebo drop (PD), after a 20-minute vocal loading task. The recovery effect by using drops was rated perceptually.

Results: The results of the self-perceived rating showed higher significant outcomes for the TD group ( $p=0.050$ to $p=0.002)$. The TD group revealed a higher agreement for perceived well-being in the throat (i.e., $83.3 \%$ ), a higher comfort in talking (i.e., $50.0 \%$ ), and lower malaise/pain in the throat (58.3\%) than the PD group (i.e., agreement of $50.0 \%, 16.7 \%$, and $20.8 \%$, respectively).

Conclusion: Thyme drops might increase the comfort, well-being in the throat, and talking after vocal loading. Further research is necessary to investigate thyme and drops as potential benefit for professional voice users with high vocal loading.

Keywords: Drops, Professional voice user, Thyme, Vocal health, Vocal loading.

International Journal of Phonosurgery \& Laryngology (2019): 10.5005/jp-journals-10023-1173
\end{abstract}

\section{INTRODUCTION}

Voice problems affect one in thirteen adults annually, and the treatment-seeking population with voice disorders is estimated up to $15 \%$ for the general population. ${ }^{1}$ For special groups (e.g., professional voice users), the values significantly increase (41$71.9 \%) .{ }^{2,3}$ The group of professional voice users comprises between $25 \%$ and $35 \%$ of the working population. ${ }^{4,5}$ Professional voice users might have a higher risk to develop voice problems than other profession groups because of their constant voice use or vocal load, and factors of work environment (e.g., high levels of background noise). ${ }^{6}$ Most frequent voice complaints for professional voice users are, for example, hoarseness, scratchy sensation in the throat, throat discomfort, and dry throat. ${ }^{6}$ Consequences of the increasing risk of communication disorders including voice problems may cost, for example, to $2.5-3 \%$ of the Gross National Product for USA per year. ${ }^{7}$ In the case of voice problems, there are several treatment methods (e.g., voice therapy and phonosurgery), which showed significant improvements in the treatment of many kinds of dysphonia. ${ }^{8,9}$ However, a quick solution for professional voice users reducing voice complaints is scarcely evaluated. For example, a dry throat or other sensations of the throat relating to the mucosa might influence voice problems, and drops can quickly increase the oral and pharyngeal humidity. Sufficient humidity is essential for a healthy voice. ${ }^{10}$ Alternative medical therapy using traditional medical care (e.g., herbs) can further assist this process to reduce health problems that affect the voice and well-being. Thyme is effective in oral treatment to alleviate the frequency and the severity of patients' cough symptoms, ${ }^{11}$ to reveal high effectiveness for the management of treatment-induced xerostomia in head and neck cancer patients, ${ }^{12}$ to exert anti-inflammatory effects in, for example, bronchoalveolar inflammation, ${ }^{13,14}$ and mucus-regulatory activity. ${ }^{14} \mathrm{~A}$ recent thyme product in the form
${ }^{1}$ Speech-Language Pathology, SRH University of Applied Health Sciences, Düsseldorf, Germany; Department of Speech-Language Pathology, Dormagen Therapy Centre, Dormagen, Germany

${ }^{2}$ Centre for Teacher Education, University of Cologne, Cologne, Germany Corresponding Author: Ben Barsties v Latoszek, Speech-Language Pathology, SRH University of Applied Health Sciences, Düsseldorf, Germany; Department of Speech-Language Pathology, Dormagen Therapy Centre, Dormagen, Germany, Phone: +49 2112807390 , e-mail: ben.barsties.v.latoszek@gmail.com

How to cite this article: Barsties v Latoszek B, v Latoszek E. Perceptual Recovery Effects of Thyme Drops after Vocal Loading for Professional Voice Users: A Randomized Placebo-controlled Single-blind Trial. Int J Phonosurg Laryngol 2019;9(2):43-46.

Source of support: Nil

Conflict of interest: Ewa $v$ Latoszek is the developer of the thyme pearls and owner of the webshop: www.shop-stimme.de, Ben Barsties $v$ Latoszek have an interest in sale through Ewa v Latoszek

of organic drops (i.e., Thymepearl [Thymianperle] by https://www. ewa-v-latoszek.de/shop/Thymianperlen-N\%C2\%B01-Liebe-DeineStimme-c36583409) was developed for professional voice users.

The aim of the present study was to explore the recovery effect of thyme pearls after a vocal loading task by presenting vocal fatigue. Self-perceived rating was used on three areas evaluating the well-being in the throat, easy talking, and a malaise or pain feeling in the throat.

\section{Materials and Methods}

\section{Subjects}

A total of 56 vocally healthy subjects ( 13 men and 43 women) were recruited from various education institutes from Düsseldorf 
and Cologne, Germany. All subjects were professional voice users according to the classification of Koufman and Issacson, ${ }^{15}$ and they had a minimal age of 18 years ranging from 25 years to 55 years. The included subjects reported no actual voice complaints before the study started or a history of voice, speech, or hearing problems or disorders. Subjects were excluded who have diabetes and allergies against food, herbs, and sugar.

This randomized placebo-controlled single-blind clinical trial consisted of a prospective study, in which every subject signed a statement of agreement and data privacy policy.

\section{Procedures}

Flowchart 1 shows the subject flow through the study. The administration of the procedure was equal for all subjects. All subjects were instructed at the beginning of the experiment (i.e., survey of vocal fatigue, vocal loading task for 20 minutes, survey of vocal fatigue, receiving a drop, and the evaluation of the drop) to avoid losing time among the sequences and, thus, possibly influencing the results. The subjects were randomly selected into a thyme drop group (TDG) and placebo drop group (PDG) without knowledge about the type and content of the drops. Before the subjects performed the vocal loading task, vocal fatigue was measured by asking each subject of their individual experience of vocal fatigue in the throat on a 7-point scale of a customized questionnaire. The scale ranges from strongly agree (i.e., 7 point) to strongly disagree (i.e., 1 point). This question was repeated after the vocal loading task to include only subjects for further analysis who experienced vocal fatigue. Just subjects who experienced vocal fatigue could evaluate the recovery effects of drops on their throat. Thus, every subject had to increase at minimally one point between the first and second measurements of the vocal fatigue rating or agreed with vocal fatigue after the vocal loading task (i.e., second measurement had a value of $\geq 5$ ).

Firstly, all subjects performed a vocal loading task for 20 minutes without breaks with a loud-presenting voice. They had to imagine using their loud voice (i.e., no screaming or yelling) for an audience (i.e., approximately 20-30 listeners) without voice amplification. During the performance, the subjects were animated to keep their individual loudness over the whole 20 minutes. They read different speeches and poems of convincing voice. Secondly, the drops were issued randomly. The subjects who were selected in the TDG received the original thyme pearls. The PDG received a $\mathrm{PD}$ with identical color, shape, and condition as the "Thyme pearl," but the content was spinach. Finally, all subjects evaluated the recovery effects of the drops in a self-perceived rating containing three customized questions. Every subject rated the recovery effect of the drops to their well-being in throat, reducing malaise/pain in the throat, and comfort in talking after vocal loading in a small survey. They were asked to answer three statements based on the three categories in a 7-point scale. The scale ranges from strongly agree (i.e., 7 point) to strongly disagree (i.e., 1 point). During the experiment, the consumption of water or other drinking/ chewing habits were excluded because of the confounding of hydration, which could influence the results. ${ }^{10}$

\section{Statistical Analysis}

All statistical analyses were completed using SPSS for Windows version 23.0 (IBM Corp., Armonk, NY, USA). The Mann-Whitney $U$ test for two independent samples was used to evaluate significant differences among the two groups. The difference between the two measurements of vocal fatigue was analyzed with the Wilcoxon signed-rank test for two related samples. The results were considered statistically significant at $p \leq 0.05$.

\section{Results}

Vocal fatigue was evaluated before the vocal tasks by an average of disagree to neutral (mean $=3.63, \mathrm{SD}=1.61$ ). A significant increasing of vocal fatigue after vocal loading was measured (mean $=4.88$, $\mathrm{SD}=1.51$, and $p<0.01$ ). However, 48 subjects reached the inclusion criteria who experienced vocal fatigue. Thus, for further analysis 48 of 56 subjects were included to evaluate the recovery effects of drops on the throat.

Table 1 shows significant differences in all three statements between the two groups. The TDG reached significant better results in all three statements than the PDG $(p=0.050, p=0.002$, and $p=0.021$, respectively).

Flowchart 1: Subject flow through the study

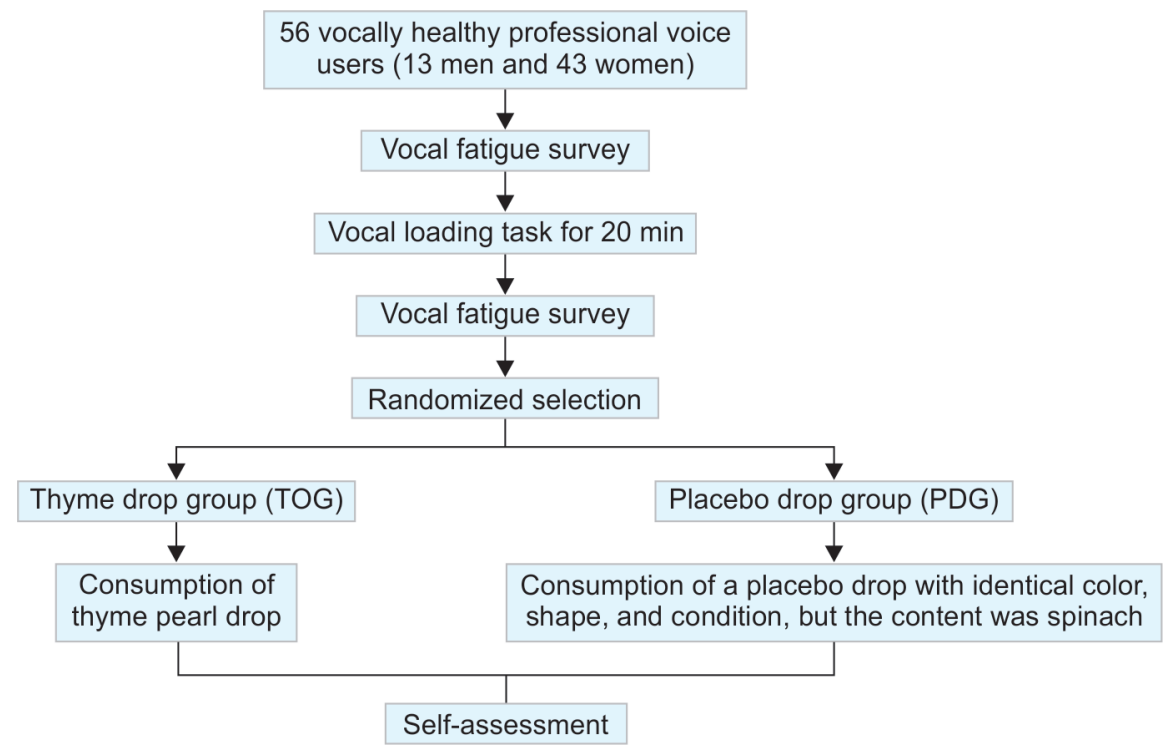


Table 1: Mean differences of the outcome of the three questions of the self-perceived rating across the two groups

\begin{tabular}{|c|c|c|c|c|c|c|}
\hline \multirow{2}{*}{\multicolumn{2}{|c|}{ Statements }} & \multicolumn{2}{|c|}{ PDG $(n=24)$} & \multicolumn{2}{|c|}{$T D G(n=24)$} & \multirow[b]{2}{*}{$Z$ score ( $p$ value) } \\
\hline & & Mean & $S D$ & Mean & $S D$ & \\
\hline 1 & $\begin{array}{l}\text { I feel that the drop increases my well-being in } \\
\text { the throat after vocal loading }\end{array}$ & 4.42 & 1.61 & 5.21 & 1.06 & $-1.941(0.050)$ \\
\hline 2 & $\begin{array}{l}\text { I feel that talking is more comfortable after } \\
\text { the consumption of the drop }\end{array}$ & 3.42 & 1.39 & 4.58 & 0.88 & $-3.089(0.002)$ \\
\hline 3 & $\begin{array}{l}\text { I do not feel malaise or pain in my throat any } \\
\text { longer after the consumption of the drop }\end{array}$ & 3.46 & 1.86 & 4.67 & 1.66 & $-2.307(0.021)$ \\
\hline
\end{tabular}

Table 2: Responses of the self-perceived rating to estimate the effects on voice and speech across the two groups

\begin{tabular}{|c|c|c|c|c|c|c|c|c|c|}
\hline Group & & atements & $\begin{array}{l}\text { Strongly agree } \\
\text { (\%) }\end{array}$ & $\begin{array}{l}\text { Nearly strongly } \\
\text { agree (\%) }\end{array}$ & Agree (\%) & Neutral (\%) & Disagree (\%) & $\begin{array}{l}\text { Nearly strongly } \\
\text { disagree (\%) }\end{array}$ & $\begin{array}{l}\text { Strongly } \\
\text { disagree (\%) }\end{array}$ \\
\hline \multirow[t]{3}{*}{ TDG } & 1 & $\begin{array}{l}\text { I feel that the drop } \\
\text { increases my well- } \\
\text { being in the throat } \\
\text { after vocal loading }\end{array}$ & 8.3 & 29.2 & 45.8 & 12.5 & 0 & 4.2 & 0 \\
\hline & 2 & $\begin{array}{l}\text { I feel that talking is } \\
\text { more comfortable } \\
\text { after the consumption } \\
\text { of the drop }\end{array}$ & 0 & 16.7 & 33.3 & 41.7 & 8.3 & 0 & 0 \\
\hline & 3 & $\begin{array}{l}\text { I do not feel malaise } \\
\text { or pain in my throat } \\
\text { any longer after the } \\
\text { consumption of the } \\
\text { drop }\end{array}$ & 12.5 & 25.0 & 20.8 & 16.7 & 8.3 & 16.7 & 0 \\
\hline \multirow[t]{3}{*}{ PDG } & 1 & $\begin{array}{l}\text { I feel that the drop } \\
\text { increases my well- } \\
\text { being in the throat } \\
\text { after vocal loading }\end{array}$ & 8.3 & 16.7 & 25.0 & 29.2 & 8.3 & 4.2 & 8.3 \\
\hline & 2 & $\begin{array}{l}\text { I feel that talking is } \\
\text { more comfortable } \\
\text { after the consumption } \\
\text { of the drop }\end{array}$ & 0 & 4.2 & 12.5 & 41.7 & 20.8 & 4.2 & 16.7 \\
\hline & 3 & $\begin{array}{l}\text { I do not feel malaise } \\
\text { or pain in my throat } \\
\text { any longer after the } \\
\text { consumption of the } \\
\text { drop }\end{array}$ & 12.5 & 0 & 8.3 & 29.2 & 20.8 & 8.3 & 20.8 \\
\hline
\end{tabular}

Table 2 shows the responses of the survey in detail to what extent agreement is reached between the two groups. The subjects of the TDG rated in $83.3 \%$ agreement for perceived well-being in the throat after the vocal loading task and consumption of the thyme pearls. The PDG reached only in 50.0\% agreement for a perceived well-being in the throat. The agreement for a higher comfort in talking was evaluated by half the subjects of the TDG after vocal effort and TD. A substantially lower level of agreement of $16.7 \%$ was found in the PDG for a higher comfort in talking using the PD after vocal loading task. Finally, to feel lower malaise/pain in the throat, the subjects of the TDG revealed a respectively high level of agreement of $58.3 \%$. Again, a clearly lower level of agreement of $20.8 \%$ rated the subjects of the PDG for a lower malaise/pain feeling in the throat.

\section{Discussion}

The present study aimed to explore the recovery effects of TDs after vocal loading for professional voice users. Thyme is an effective herb because of the contribution of thymol and carvacrol in thyme, which possess a concentration-dependent antispasmodic effect in smooth muscles (e.g., trachea). ${ }^{16}$ Furthermore, thyme showed success in other studies with benefits such as, for example, antiseptic, antibacterial, and anti-inflammatory. ${ }^{17}$ Particularly, the anti-inflammatory effect of thyme might confirmed the present findings, because inflammation increases through vocal loading and might have an impact on phonotrauma or voice problems. ${ }^{18}$ Avoiding that no vocal fatigue or differences in the experience of vocal fatigue across the two groups existed before and/or after the vocal loading task, the present study considered this aspect, in which the included subjects revealed comparable conditions of vocal fatigue. Thus, the circumstances to evaluate the drops were equal for both groups. The questions after the vocal loading task considering well-being in the throat, higher comfort of talking, and no malaise or pain in the throat were significantly higher for the TDG than PDG. The subjects of the TDG showed in mean an agreement of an improvement of the TDs for their vocal production after vocal loading. The PDG reached a mean result of neutral to disagreement of vocal production improvement with the PD. Thus, it seems that 
the ingredients in drops are necessary than sucking alone to receive, for example, lower concentration of inflammation.

The present results of the randomized control trial study showed that there might be a benefit using TDs as quick solution to regenerate after vocal loading for professional voice users.

Although the results from this study are intriguing and allow us to describe the associations of the effectiveness of using TDs as a quick solution to regenerate after vocal loading, we cannot generalize the present effects. In addition to this specific limitation, a number of additional limitations should be acknowledged. Firstly, there is a lack of laboratory measures (e.g., histology) to control the concentrations of inflammatory mediators. Secondly, limitation is the absence of instrumental assessments such as laryngeal imaging (i.e., laryngoscopic, laryngostroboscopic, videokymography, and high-speed digital imaging), acoustics, and aerodynamics as recommended by the American Speech-Language-Hearing Association. ${ }^{19}$ In the absence of such imaging, it is impossible to know the true status/health of the vocal folds and surrounding structures. Thus, the findings would have been strengthened by additional information regarding laryngeal/vocal structure and physiology. Acoustics and aerodynamics are sensitive to the severity of disturbances in voice production and can provide indirect inferences regarding the underlying pathophysiology of voice disorders. Future studies should include instrumental methods to place these results in context. A third limitation is the absence of a follow-up measurement. In future studies, a follow-up measurement should be implemented to assess the effectiveness on the voice constitution of professional voice users to use TDs.

However, the general recovery effect of drops on the vocal tract is relatively unknown and more research is needed to attain more knowledge of drops as benefit for vocal production.

\section{Conclusion}

Thyme drops might have a positive effect for the well-being and reducing malaise/pain in the throat after vocal loading. This might also be a reason for a higher comfort level in talking after vocal effort. However, further research is necessary to investigate thyme and drops as potential benefit for professional voice users or other groups (e.g., dysphonia) with high vocal loading or tendency to voice complaints.

\section{References}

1. Bhattacharyya $\mathrm{N}$. The prevalence of voice problems among adults in the United States. Laryngoscope 2014;124(10):2359-2362. DOI: 10.1002/lary.24740.

2. Van Houtte E, Van Lierde K, D'Haeseleer E, et al. The prevalence of laryngeal pathology in a treatment-seeking population with dysphonia. Laryngoscope 2010;120(2):306-312.

3. Mozzanica F, Ginocchio D, Barillari R, et al. Prevalence and Voice characteristics of laryngeal pathology in an Italian Voice Therapy- seeking population. J Voice 2016;30(6):774.e13-774.e21. DOI: 10.1016/j.jvoice.2015.11.018.

4. Titze I, Lemke J, Montequin D. Populations in the U.S. Workforce who rely on voice as a primary tool of trade: a preliminary report. J Voice 1997;11(3):254-259. DOI: 10.1016/S0892-1997(97)80002-1.

5. Vilkman E. Voice problems at work: a challenge for occupational safety and health arrangement. Folia Phoniatri Logop 2000; 52(1-3):120-125. DOI: 10.1159/000021519.

6. Wingate JM, Brown WS, Shrivastav R, et al. Treatment outcomes for professional voice users. J Voice 2007;21(4):433-449. DOI: 10.1016/ j.jvoice.2006.01.001.

7. Ruben RJ. Redefining the survival of the fittest: communication disorders in the 21st century. Laryngoscope 2000;110(2 Pt 1):241-245. DOI: 10.1097/00005537-200002010-00010.

8. Desjardins M, Halstead L, Cooke M, et al. A Systematic Review of Voice Therapy: What "Effectiveness" Really Implies. J Voice 2017;31(3):392. e13-392.e32. DOI: 10.1016/j.jvoice.2016.10.002.

9. Friedrich $G$, Remacle $M$, Birchall $M$, et al. Defining phonosurgery: a proposal for classification and nomenclature by the Phonosurgery Committee of the European Laryngological Society (ELS). Eur Arch Otorhinolaryngol 2007;264(10):1191-1200. DOI: 10.1007/s00405-0070333-x.

10. Alves $M$, Krüger $E$, Pillay $B$, et al. The effect of hydration on voice quality in adults: a systematic review. J Voice 2019;33(1):125.e13-125. e28. DOI: 10.1016/j.jvoice.2017.10.001.

11. Wagner L, Cramer H, Klose $\mathrm{P}$, et al. Herbal medicine for cough: a systematic review and meta-analysis. Forsch Komplementmed 2015;22(6):359-368. DOI: 10.1159/000442111.

12. Charalambous $A$, Lambrinou E, Katodritis $\mathrm{N}$, et al. The effectiveness of thyme honey for the management of treatment-induced xerostomia in head and neck cancer patients: A feasibility randomized control trial. Eur J Oncol Nurs 2017;27:1-8. DOI: 10.1016/j.ejon.2017.01.001.

13. Seibel J, Pergola C, Werz O, et al. Bronchipret ${ }^{\oplus}$ syrup containing thyme and ivy extracts suppresses bronchoalveolar inflammation and goblet cell hyperplasia in experimental bronchoalveolitis. Phytomedicine. 2015;22(13):1172-1177. DOI: 10.1016/j.phymed.2015.09.001.

14. Seibel J, Kryshen K, Pongrácz JE, et al. In vivo and in vitro investigation of anti-inflammatory and mucus-regulatory activities of a fixed combination of thyme and primula extracts. Pulm Pharmacol Ther 2018;51:10-17. DOI: 10.1016/j.pupt.2018.04.009.

15. Koufman JA, Isaacson $G$. The spectrum of vocal dysfunction. Otolaryngol Clin North Am 1991;24(5):985-988.

16. Begrow F, Engelbertz J, Feistel B, et al. Impact of thymol in thyme extracts on their antispasmodic action and ciliary clearance. Planta Med 2010;76(4):311-318. DOI: 10.1055/s-0029-1186179.

17. Salehi B, Mishra AP, Shukla I, et al. Thymol, thyme, and other plant sources: Health and potential uses. Phytother Res 2018;32(9): 1688-1706. DOI: 10.1002/ptr.6109.

18. Verdolini Abbott K, Li NY, Branski RC, et al. Vocal exercise may attenuate acute vocal fold inflammation. J Voice 2012;26(6):814. e1-814.e13. DOI: 10.1016/j.jvoice.2012.03.008.

19. Patel RR, Awan SN, Barkmeier-Kraemer J, et al. Recommended protocols for instrumental assessment of voice: american speechlanguage-hearing association expert panel to develop a protocol for instrumental assessment of vocal function. Am J Speech Lang Pathol 2018;27(3):887-905. DOI: 10.1044/2018_AJSLP-17-0009. 